\title{
Temporal Enforcement of Court Ruling in the Jordanian Law
}

\author{
Dr. Alaa’ Bani Younes \\ Jerash University
}

\begin{abstract}
The description of implementation problems applies to any dispute related to implementation and focuses on it, regardless of the person who presented the problem. Implementation problems may be temporary or objective depending on the nature of the request, as well as that each dispute in implementation has two aspects, a temporary face and an objective aspect. If the debtor fulfills the debt after the issuance of the ruling, he may raise a temporary problem in which he requests a temporary stay of execution without deciding on the claim to repay the debt, and the judgment may invalidate the execution in order to fulfill the debt and absolve him of his liabilities. The time until the issue of the dispute is decided upon, such as a ruling to continue the execution until the verdict is correct or the ruling to suspend the execution until it is ruled invalid. That is if it is submitted to the judge of urgency to adjudicate it with a temporary ruling without prejudice to the origin of the right, before completing the implementation process.
\end{abstract}

Keywords: Execution, objectivity, debtor, creditor, nullity, judge of urgency>

DOI: $10.7176 / \mathrm{JLPG} / 102-06$

Publication date:October $31^{\text {st }} 2020$

\section{Introduction}

What happens is that the conditions required by the executive bond may not be met together, and that the original bond is not with the creditor, or it is executed on funds that are not owned by the debtor, or the execution is carried out on funds that may not be seized, without following the procedures and formalities required by law.

In order to achieve justice and equality among the parties to the implementation, the Jordanian legislator organized and gave the chief executioner the power to decide on the problems that obstruct the implementation, until the allegations related to the implementation are decided, in those disputes, whether temporary or substantive.

Execution problems are not considered to be an appeal against the judgment to be executed, but rather are disputes related to the conditions required by the law to be fulfilled to carry out the implementation. The dispute and whether it is ruling as a judge of urgent matters, or ruling as a judge of the issue.

The importance of the research shows that the Jordanian legislator has adopted the method of expressing the problem with the usual procedures for filing cases, i.e. by depositing the case sheet in the clerk of the competent court of execution, and registering it in the records designated for that, as is the case with regard to filing urgent cases $^{1}$.

The problem is considered raised in this case from the time it was presented before the executor, and therefore if the problem appears before the completion of the implementation, then it is acceptable and the judge of urgent matters considers it and issues a judgment regarding it even if the executor continues in the execution until its end after raising the problem before him. Those that were taken by the executor after the problem was expressed shall be extinguished retrospectively.

The objection of the garnishee to the execution by raising a temporary problem, regardless of the way followed in raising it, does not lead to a stay of execution in the Jordanian law. Rather, the execution procedures continue despite the objection to it and despite its filed before the execution judge, the judgment of the execution chief is the one that stops the procedures if the conditions for accepting the problem are met My time.

\section{Research problem}

It appears when the problem arises during the execution, which is the prevalent matter such as temporarily suspending execution or continuing it temporarily, or that seizure is carried out on funds that are not owned by the debtor, or that it is not permissible to seize them, or to request the invalidation of some implementation measures that have been taken and are in violation of the law.

Considering that these problems are subsequent facts to be the document according to which the execution is to be carried out. If the executive document is a court ruling, then the implementation problem must be based on matters that occurred after the issuance of this ruling. To be re-submitted to the judiciary except through one of the extraordinary methods of appeal stipulated by law. ${ }^{(2)}$

We must address these problems and this is what I will explain in the first topic.

The first topic: the legal concept of implementation problems

The implementation law did not know the executive problem. Article (19) of the implementation law

${ }^{1}$ Al-Husseini, Urgent Cases, pp. 57-58

${ }^{2}$ Fathy Wali, 1968, Forced Execution 
authorized the chief of execution to deal with all temporary disputes and problems encountered in implementation, and distinguished in this between temporary disputes and problems encountered in implementation, that is, everything that emanates from the implementation itself and aims to object to the measures taken or to reject Taking it by requesting a temporary measure that suspends the execution and between the substantive disputes that obstruct the execution, and as a result of deciding on them, the execution becomes permissible or not permissible, correct or invalid, and which is decided by the courts of the matter, such as the case for the entitlement of the seized funds ${ }^{1}$.

Implementation problems are issues related to implementation that deal with legal difficulties, not material difficulties, because the decision on material difficulties is within the competence of the execution officer who has the use of compulsory force in order to achieve this matter ${ }^{2}$.

Jurisprudence has dealt with many opinions about the definition that should be given to the meaning of implementation problems. Another opinion goes to the fact that implementation problems are stories related to implementation, as they are allegations before the execution judiciary, as they have affected the implementation, negatively or positively, such as claiming the nullity or validity of the execution, and asking to stop it, limit it, or continue it. ${ }^{(3)}$

Another aspect of jurisprudence believes that execution disputes are the objections or requests that one of the execution parties or others adhere to on the occasion of an executive case or execution litigation, and the execution judge shall decide on it by a judicial ruling that has an effect on the executive lawsuit and the execution litigation. ${ }^{(4)}$

Another aspect of jurisprudence believes that execution disputes are the objections or requests that one of the execution parties or others adhere to on the occasion of an executive case or execution litigation, and the execution judge shall decide on it by a judicial ruling that has an effect on the executive lawsuit and the execution litigation. (5)

As for the prevailing opinion, it is defined as disputes related to the implementation of executive bonds that are raised to the judiciary by one of the parties in the face of the other party or raised by others in their confrontation, and the ruling therein results in stopping the course of implementation or its continuation, or the execution becomes valid or null, permissible or not). ${ }^{(6)}$

Consequently, it becomes clear that the implementation problems are disputes that arise on the occasion of compulsory execution and are related to the availability of the necessary conditions for its conduct, expressed by the execution parties or others. ${ }^{(7)}$

Based on the aforementioned and through the jurisprudential opinions we have mentioned above, all focused on the fact that the elements of implementation problems can be summarized in:

- Execution problems are related to compulsory execution, as they arise on the occasion of execution and focus on one of his procedures. Therefore, they are presented to the execution judge to decide on them with a ruling that affects either positively or negatively.

We must explain the most important characteristics that may apply to implementation problems, and this is what I will address in the first requirement.

\section{The first requirement:}

\section{The characteristics of implementation problems}

All the jurisprudential opinions are unanimously agreed that implementation problems are disputes that arise due to forced implementation. It raises litigation over the enforcement judiciary and that it has common characteristics that apply to all problems, whether temporary or objective.

These characteristics can be summarized in the following elements:

First: These problems are considered among the legal obstacles or objections, that is, they are allegations that are presented to the execution judiciary for adjudication, as they are not material obstacles intended to prevent execution because these obstacles are not executive disputes and are not brought before the judiciary, and the executor overcomes the material obstacles with the help of the public authority that helps him To carry out the implementation and provide him with the necessary assistance to achieve this ${ }^{(8)}$.

Second: The implementation problems relate to the conditions that the law requires for the implementation of the implementation, as well as the implementation procedures that must be taken, and thus disputes affect the

\footnotetext{
${ }^{1}$ Muhammad Hamid Fahmy, No. (104) Ramzi Saif No. (165), Sharqawi No. (103) Glasson No. (103), Fathi Wali. Dr.. Muflih Al-Qudah, p. (32).

${ }^{2}$ Implementation principles in accordance with the latest amendments to the implementation law.

${ }^{3}$ Ahmad Abu Al-Wafa (1980), Procedures for Enforcement in Civil and Commercial Matters Under the Lebanese Code of Procedure, p. 237).

${ }^{4}$ Anwar Tolba, Forced Execution and Its Objective and Temporary Disputes, p.9.

${ }^{5}$ Fathi Wali, Forced Execution (1989), p. 4.

${ }^{6}$ Ismail Omar, Problems of Forced Execution, p. 18

${ }^{7}$ Ashour Mabrouk, Forced Execution in the Law of a State Like the Arab Emirates, p. 402

${ }^{8}$ Al-Halabi Publications, The Executive Problem, p. 42.
} 
implementation process, such as implementation under a ruling that is not permissible for implementation ${ }^{(1)}$.

Third: These problems may arise during implementation, but they may arise before starting it, as the dispute in this case is a preventive measure from a possible action ${ }^{(2)}$.

Example: When a third party complains about the execution before starting it, such as a lawsuit not to impose seizure filed by a third party who is claiming a right to the money requested to be seized, and in which the judgment is requested on a temporary basis not to impose the seizure, in cases where the invalidity of the attachment is apparent $^{(3)}$.

Fourth: Implementation problems are not one of the methods of appealing against judgments and judicial orders. Implementation problems are aimed at objecting to enforcement procedures that do not comply with the law, as it is an objection to the procedures of executive activity. ${ }^{4}$

Fifth: The description of implementation problems applies to any dispute related to implementation and is focused on, regardless of the person who presented the problem, it may be presented by the executor against him, against the execution applicant to prevent or suspend the implementation due to the lack of conditions stipulated by the law, and it may be raised from the applicant for execution and may be raised by others ${ }^{(5)}$.

Sixth: The implementation problems may be temporary or objective according to the nature of the request, i.e. the required legal protection, in addition to that each dispute in implementation has two sides, a temporary face and an objective one. If the debtor fulfills the debt after the judgment is issued, he may raise a temporary problem in which he requests a temporary stay of execution without deciding on the claim to repay the debt, and the judgment may be requested to nullify the execution in order to fulfill the debt and acquit it. ${ }^{6}$

The question arises about the legal adaptation of these problems, and this is what I will discuss in the second requirement.

The second requirement:

The legal description of the implementation problems.

Executive protection is the last stage of judicial protection and it does not arise except by using the right to compulsory execution, which is considered a power granted by law to a person who possesses an executive document and can move the judicial apparatus in the state to match his de facto position over his legal position ${ }^{(7)}$.

Implementation problems do not affect the substantive right to amendment, change or addition, and therefore they do not have a direct impact on the substantive rights that compulsory implementation proceeds according to their necessity ${ }^{(8)}$.

The temporary problems aim to obtain an urgent temporary judgment, the content of which is the order to take a temporary or conservative measure until it separates the substantive problem on which the temporary problem is based ${ }^{(9)}$.

As for the substantive problem in the implementation, it aims to obtain a ruling regarding the validity of the execution or its invalidity of its permissibility or its impermissibility, it is based on the reasons related to the objective conditions that must be met by the permissibility of the seizure or its impermissibility and invalidity and that the ruling required to be executed is it not legally enforceable then it does not address the origin The right to any amendment, change or addition

Consequently, implementation problems are subject to special procedures that the law may stipulate or general procedures for ordinary litigations. The judge also enjoys in these disputes the powers he enjoys for regular litigation.

The finest statement is that the implementation problems are a judicial dispute in the correct sense, that is, it is a real case between the applicant and the executioner against him, and it is similar to the lawsuit that arises between the plaintiff and the defendant and its procedure is characterized by being of a purely formal nature, so the principle of confrontation is not applied to the same extent as it is applied in the original lawsuit and therefore Its procedures should be carried out under the supervision of the judicial authority ${ }^{(10)}$.

These problems are not directly applied to the substantive right, even if it hinders obtaining it temporarily by affecting the execution litigation procedures, which is considered the technical tool through which the creditor

\footnotetext{
1 Fathi Wali, 1968, Forced Execution in Lebanese Law

${ }^{2}$ Dr.. Abdel Fattah Azmy, Rules of Forced Execution, p.897.

${ }^{3}$ Dr.. Al-Hadidi, Algebraic Execution, p. 455.

${ }^{4}$ Dr. Al-Hadidi, Forced Execution and Distribution Procedures, p. 457, and Dr. Haydar Nusrat Manla

${ }^{5}$ Dr. Fathi Wali forced execution, p. 35

${ }^{6}$ Resolution 997-94-dated 5/18/1994, where the Amman Court of Appeal ruled:

"The submission of a preliminary lawsuit to prevent the claim of the value of the proposed bill for execution, Submitting an urgent request to suspend execution makes this request worthy and deserving of response.

${ }^{7}$.Fathi Wali, The Forced Execution, p. 24

${ }^{8}$ Dr.. Ismail Omar, Problems of Forced Execution, p. 106.

9 Dr.. Muhammad Ratib 1972, Urgent Matters Court.

${ }^{10}$ Dr.. Fathi Wali, Forced Execution in Lebanese Law, p. 592.
} 
obtains his right compulsorily on the debtor.

This adaptation has the following consequences:

1. The problem of implementation does not begin without an independent request, whether from the parties to the implementation or from others, and it must fulfill the necessary conditions.

2. The implementation problem is subject to the general procedures and rules in the ordinary litigation.

3. The judge enjoys with regard to these problems the powers he enjoys in the general litigation, and what he issues a court ruling shall have the same authority as the judicial rulings.

This adaptation to the implementation problems was taken by the Jordanian legislator, as it stipulated in Article (19) of the Execution Law, "The President shall settle the temporary disputes and the dilemmas that obstruct the implementation." The Jordanian legislator introduced this text by quoting from Article (275) of the Egyptian Procedure Law, but the competence of the chief of execution was limited. On the temporary implementation problems without being exposed to objective problems. We must discuss other legal systems and the importance of differentiating between implementation problems and legal systems, and this is what I will explain in the second topic. ${ }^{(1)}$

The second topic: the distinction between implementation problems and other legal systems after defining the concept of implementation problems and legal establishment of them, it is necessary to distinguish between them and the methods of appeal and disputes related to the interpretation of the judgment to be implemented and disputes of the executive force.

\section{The first requirement: to distinguish between implementation problems and appeal methods}

The methods of appeal are the means specified by the law to review judicial rulings to remove the defects and fix the errors they may have. The general rule is that it is not permissible to appeal judgments except through the methods of appeal decided by the legislator, because the judgments are authentic and they are prevented from violating them except through these methods. Rather, the appeal litigation is considered a stage of the executive document itself, since the judgment does not accept compulsory enforcement as a general rule unless it has acquired certain procedural immunity by exhausting the regular methods of appeal ${ }^{(2)}$.

Therefore, the execution judge does not have jurisdiction to appeal judgments because it is not an appealing party, and when he looks into the implementation problems, he does not consider them as a party to appeal the ruling, as implementation problems are not considered a grievance from the judgment, but in many cases they are considered grievances from execution ${ }^{(3)}$.

in spite of the similarity of the implementation problems and the methods of appeal in that they lead to the suspension of the execution of the executive document if it is a judgment, there are basic differences that can be summed up in the following that the implementation problems are a means given by the law to the parties to the implementation and to others in order to enable them to present their claims before the execution judiciary if the elements of the execution are too weak or Its introductions or procedures are defects that affect his safety with the intention of preventing, stopping or nullifying the implementation that does not comply with the law. As for the appeal of judicial rulings, it is an objection to the soundness of the judgment in terms of form or subject matter, and the appeal of judgments is regulated by the legislator in a specific way and determines the jurisdiction for its consideration of a specific court and this appeal is not It takes the form of an objection to the implementation of this judgment, but it takes the form of an appeal directly to this judgment. The appeal here is directed to the form or content of the judgment and is not directed to the execution procedures. ${ }^{4}$

The judge in charge of examining implementation problems has no jurisdiction when considering the appeal of the judicial ruling that is considered an execution document, and to say otherwise is a waste of the authority of the judgments ${ }^{(5)}$. The essence of the execution problem differs from the essence of appealing against judicial rulings considered as evidence. There is nothing to prevent a problem from being raised in the implementation of a judicial ruling and appealing against this judgment by one of the methods of appeal against judgments due to the different nature of the challenge and the problem ${ }^{(6)}$.

it is noticed in this regard that the acceptance of the judgment on the part of the convicted person, even if he forfeits his right to challenge this judgment, but that does not prevent him from contesting the implementation of the same judgment because the previous acceptance issued by this person only deals with dropping the right to appeal without prejudice to his right to dispute In implementing the same ruling ${ }^{(7)}$. However, it may relate to obstacles related to the interpretation of the ruling, which I will explain in the second requirement.

\footnotetext{
${ }^{1}$ Dr.. Omar, Problems of Implementation, pp. 44-46

2 Azmi, Rules of Forced Execution, p.695

${ }^{3}$ Hashem, Litigation and Execution Procedures, p. 340.

${ }^{4}$ Omar, Problems of Forced Execution, p. 20.

${ }^{5}$ Azmi, Nizam Al-Qadi Execution, p. 434.

${ }^{6}$ Omar, Problems of Forced Execution, p. 20.

${ }^{7}$ Wali, Algebraic Execution, p. 434.
} 
The second requirement: the difference between implementation problems and disputes related to the interpretation of the judgment to be implemented

The execution judge does not have the original jurisdiction over the interpretation disputes. The original jurisdiction of interpretation is held by the court that issued the judgment, so a problem may arise in the implementation of the executive document before the chief of execution.

The implementation problems differ from the disputes related to the interpretation of the judgment in which the judgment is to be executed, its correction, or the dispute in its description, so the interpretation of the ambiguity of the words of the verdict or the correction of the material errors contained therein, or the grievance of the wrong description that has been inflicted on the judgment, all of these issues cannot be considered as problems in the implementation of the judgment Judicial and the reason for that is that these disputes precede the judicial implementation process itself. This is evident in the case of a request for interpretation of the judicial ruling, as all the plaintiff's requirement is focused on giving a proper interpretation of the verdict in light of the facts that the judge has decided.

With regard to the correction of the judgment, all that is required is focused on correcting the material errors mentioned in the judgment only, without prejudice to the essence of the judiciary mentioned in this ruling. Therefore, the correction faces issues prior to the judicial implementation.

As for grieving against the description of the judicial ruling, it is a special way to appeal the judgment to correct a mistake made by the court when describing the judgment, so it is not permissible to dispute the implementation on the basis of the error in describing the judgment due to the different nature of the dispute in the implementation that is directed to its procedures, and therefore there is nothing to prevent resorting to The two roads simultaneously ${ }^{(1)}$.

The basic principle is that it is not permissible to implement the judgments that accept the appeal by regular methods. Final judgments are those that are suitable for implementation despite the permissibility of appealing against them by extraordinary methods of appeal. The rule is an exception related to the implementation of judgments subject to appeal by appeal and that if they are included in expedited enforcement, as these provisions provide executive power, and this is what it stipulated Article (9) The Jordanian Execution Law: "It is not permissible to enforce bonds as long as it is permissible to challenge them unless the expedited execution is stipulated in the law or is governed by it." The Jordanian legislator introduced his quotation from Article (287) of the Egyptian Procedure Law, which confined it to rulings This is in contrast to the Jordanian legislature, as it includes official and regular rulings and other execution documents and commercial papers ${ }^{(2)}$.

By disputes of the executive force in the ruling, it is intended to appeal against the description of the judgment, that is, in terms of what it has decided in terms of enforcement or bail, or in terms of its being primary or final. If the opponent increases to challenge this description, that is, he raises a dispute related to his executive power, then he has nothing but to take the path of appeal from the judgment by requesting Stopping its enforcement, and the court to which this grievance is referred may order the suspension of the execution if it is feared that serious harm will occur from the execution, and if the reasons for challenging the judgment or the order are more likely with them to cancel it ${ }^{(3)}$.

Grievance against the description of the judgment is not considered one of the implementation problems. Therefore, if the judgment is wrongly described as final while it is preliminary, it is not permissible to express a grievance against this description through a dispute in the implementation. Rather, the path specified by the legislator for this must be followed, which is the appeal to the Court of Appeal to which the court that issued Judgment ${ }^{(4)}$.

The dispute in the executive force of the ruling is similar to the execution disputes in that they are forms of temporary protection and that they lead to the suspension of execution temporarily, but the subject of (the dispute in the executive force) of the ruling differs from the issue of implementation problems, so the first responds to the ruling in terms of its validity for implementation on the same implementation and what is marred by the request for a stay Execution shall be submitted to appeal the judgment, i.e. when the judgment is final or enforceable in an expedited manner. As for the problem of execution, it is accepted whether the judgment is appealed or not ${ }^{(5)}$.

The determination of the judge competent to examine the problems of implementation is mainly related to the type of problem. If the problem is temporary, in which the litigant demands merely taking a temporary measure to stop the execution in a way that does not affect the origin of the disputed right that the head of execution is concerned with in the Jordanian implementation law.

The type of problem is also reflected on the judge's authority in the eyes of the execution problem, and it shows the pronunciation in which he works when he looks at it. It also reflects on the nature of the judgment he

${ }^{1}$ Omar, Problems of Forced Execution, p. 23

2 Al-Aboudi, Abbas, (2005), Explanation of the provisions of the Execution Law - a comparative study -, Dar Al-Thaqafa, p. 188.

${ }^{3}$ Thabet, Younes, (BS), Problems of Execution in Verdicts and Documents, and the Execution Judge System, Alam Al-Kitab, Cairo, pp. 14-15..

${ }^{4}$ Al-Nidani, Al-Ansari Hassan, (2001), Direct Execution of Executive Bonds, New University House, Alexandria, p. 263.

${ }_{5}$ Azmi, Execution Judge, p. 323. 
issues to decide on this problem, but more than that, the type of problem has an effect on the execution procedures at a stage prior to the judge's consideration of this problem.

The temporary problem must be raised before the completion of the execution or immediately after the executive document acquires its executive power. If it is a judgment, it must be considered as an executive document that he possesses the power of the decided thing. Execution for any reason shall suspend execution, and a third party who was not a party to the judgment or the document with which it was executed may raise a temporary problem in the execution if it appears to him from the actions and actions of the execution applicant that he wishes to execute a certain money over which he has a right, whether it is ownership or possession. ${ }^{1}$

Temporary implementation problems may deal with implementation procedures in terms of the lack of conditions for their validity or the failure of a basic procedure of its procedures or its absence, and the problem in it demanded the suspension of implementation or insists that the procedures are sound and free of defects and calls for continuation of implementation in this problem does not demand the invalidity of the procedures or their validity. He builds the temporary problem on it only and adheres to his requests for judgment. ${ }^{2}$

The temporary nature of implementation problems requires the necessity of the general conditions for accepting urgent cases. The execution judge is obliged to respect the restrictions that the judge of urgent matters adheres to in the consideration of this type of dispute that the urgency and preponderance of the right to exist and that what is required is a temporary procedure in addition to the necessity to raise the temporary problem before the completion of the implementation and the necessity of litigation The Obligor in the Executive Deed for the problems raised by others ${ }^{(3)}$.

These conditions must be met so that the execution judge can look into the temporary implementation problems, and the judge is the one who assesses the availability of these conditions, as he does not adhere to the legal descriptions that the litigants give to their claims except to the extent that these descriptions are consistent with the facts of the dispute.

If the execution judge concludes that the presented dispute is a temporary problem in the execution, he shall rule with his competence to look into this problem and decide on it as a judge for urgent matters. But if it ends to the failure of these conditions and that what is presented to him is not a temporary problem, then he shall rule not to accept the problem without the need to examine the matter. The rejection is not judged because the refusal is judged in the matter. ${ }^{4}$

Acceptance of temporary problems before the commencement of the implementation, and even before taking the implementation introductions that are represented in the declaration of the executive bond to the debtor to assign him to fulfill. The dispute over this imposition is not directed to the implementation procedures, but rather is directed to the executive force of the executive document. Temporary problems may also be accepted throughout the implementation phase. This is The natural time to progress with implementation problems. ${ }^{5}$

But if the execution has been completed, there is no meaning in the request to suspend it, and there is no meaning to the request for its continuation, because the temporary problem aims to obtain a temporary stay of execution or to continue with it temporarily. ${ }^{6}$

If it happens that the implementation has taken place in relation to some procedures, the temporary problem is not accepted regarding what has been done, but rather it is accepted only in relation to what has not been completed, but if it happened that the temporary problem was raised during the implementation, that is, the implementation was not completed the moment the temporary problem was raised, but after the presentation of the problem and before The ruling on it has been implemented. Is the temporary problem acceptable in this case or not?

An opinion went to the non-acceptance of the temporary problem of lack of interest due to the impossibility of implementing the judgment issued on it by responding to the opponent's request. ${ }^{7}$

We conclude from all of this that several conditions must be met in order for the temporary problem to be accepted. It must be lifted by the person of his character, and the person who raises the problem must have an interest, whether personal or direct, and that it be lifted before the completion of the implementation, and that it is urgent. The temporary implementation problems are all urgent problems, meaning that the law supposes the availability Urgency in it.

The temporary problem in execution is raised as a general rule, and the urgent dispute is referred to the judiciary, i.e. by the normal way to file urgent cases, given that the execution judge in this case looks at the problem as a judge of urgent matters ${ }^{8}$.

\footnotetext{
1 Taheri Civil Procedures Brief, pp. 159-160

2 Dr. Omar Ismail Problems of Forced Execution, p. 62

${ }^{3}$ Omar, Abdel Khaleq, (1978), General Principles of Implementation, University Press, Cairo, p. 38.

4 Omar Problems of Implementation p. 38

${ }^{5}$ Omar Ismail problems of forced implementation

${ }^{6}$ Fathi Wali of Compulsory Execution, p. 284, and also (Seif, Ramzi) Rules for organizing documented documents, p. 284

${ }^{7}$ Abu Al-Wafa Theory of Defenses, p. 383

${ }^{8}$ Salah Al-Din Shushar Y Al-Wafi in Execution Law, p. 119
} 
The Jordanian legislator stipulated in Article 18 of the Execution Law that: "The President shall decide on all executive requests based on the file papers without inviting the litigants," meaning that the Jordanian legislator kept the original procedures for raising temporary execution problems, so that it is raised to the chief executioner with the usual procedures for filing cases Expedited, that is, by creating the case sheet with the clerk of the competent court, and the person who raises the problem must attach with his request a bank or legal guarantee presented by a full guarantor that guarantees the damage and damage that may befall the convicted person in the executive case if it appears that the plaintiff is not right in his lawsuit with the exception of official and public institutions and municipalities And banks operating in the Kingdom of Jordan from the guarantee requirement according to the text of Article (33/2) of the Jordanian Code of Civil Procedure.

We believe that the position of the Jordanian legislator to keep the original in the procedures for raising temporary problems of implementation so that it is raised before the chief of implementation through the usual procedures for filing urgent cases, and the position of the Egyptian legislator who, in addition to the regular way, allowed for the possibility of expressing the temporary problem in front of the record during the implementation process in order to achieve many purposes, the most important of which is facilitation of Litigants and reconcile between the interest of the applicant for execution and the interest of the objected against him, by assisting the opponent who was unable to raise the problem before starting the execution, by remedying his matter and providing him with the hand of assistance by permitting raising the problem in the immediate manner in front of the report during his initiation of the execution.

As a result of merely raising the temporary execution problem to the court, the chief executioner (the judge of urgent matters) is obligated to look into it and decide thereon with the authority he has when ruling on the temporary procedures whenever the subject matter falls within his jurisdiction or not.

The lifting of the temporary problem in execution will result in a court having jurisdiction over it, excluding all the other courts, so that if the same problem is raised to another court, it is permissible to argue before this last court by referring the dispute to the first court to which the dispute was raised. ${ }^{1}$

But what is the nature of the ruling issued in the temporary problems? This is what we will discuss in the third topic.

\section{The third topic: The Nature of The Ruling Issued in The Temporary Problem}

The chief of execution shall decide on the temporary implementation problems according to the text of Article (18) of the Jordanian Execution Law in his capacity as a judge for urgent matters. Therefore, his jurisdiction over these disputes is limited to the temporary procedures that he fears from the lapse of time to ward off an imminent danger or to maintain a legitimate actual situation or to maintain a legal center This exists without prejudice to the origin of the right. ${ }^{2}$

He shall not be subject to the reasons for his judgment to adjudicate the issue of the dispute, or base his judgment in the temporary request on causes that affect the origin of the right, or be subject to documents submitted by one of the litigants.

The head of execution has the right to discuss the dispute on a temporary basis, not to settle it with a decisive ruling for the dispute, but to improve from it the correctness of the temporary procedure required in it, so he decides to guide it by stopping or continuing the implementation and estimating this time that does not affect the disputed right and the chief executioner may rely on the apparent meaning of what is presented to him. Documents, he does not have to, if he relied to justify his judgment in the provisional procedure, on a written testimony the signatory determines certain facts, and he has the right to examine the documents of the litigants and the arguments they present, provided that his search is incidental to the sensitivity of what is likely at first sight.

But what are the defenses that the complainant or the complainant may raise against him before the competent court, we will explain this in the following.

\section{The first requirement: the ruling on the defenses and requests of the complainant other than what the problem was raised with}

What is meant by the defenses here are the defenses that the respondent expresses against him in terms of defenses that refute the requests of the problem, and these defenses may not be related to public order, so the court does not pay attention to them unless the respondent is exposed to them against him, and these defenses may be related to the public order, so the court is exposed to them on its own and the first is dropped by speaking on the subject while The second does not lapse and can be raised even for the first time before the court. As for the problem's requests other than what the problem has been raised with, what is meant by the problem's requests are the symptoms that arise during the consideration of the problem, such as the respondent's response to the request for the implementation of the judgment in which he is being questioned. What was presented in detail is as follows ${ }^{3}$ :

\footnotetext{
${ }^{1}$ Salah Al-Din Shushar Y Al-Wafi in Execution Law, p. 119

${ }^{2} \mathrm{Al}$-Aboudi Explanation of the provisions of the Execution Law, p. 180

${ }^{3}$ Zahiri, Temporary Execution Problems Related to the Implementation of Judgments of the State Council Courts, pp. $140-142$.
} 


\section{1) Plea for lack of specific jurisdiction and referral:}

The general rule in Jordanian law is that the jurisdiction to consider temporary execution problems is held for the chief of execution in the circuit of the court that issued the judgment, and therefore in the event that the temporary problem is raised to a court that is not different from his consideration, the competent court has to look into it whether he has paid in front of it with lack of jurisdiction or not paid, and was exposed to it on its own accord In order to attach this push to public order. ${ }^{1}$

2) Failure to accept the problem: If the interest of the uploader has denied the temporary problem, its characteristic, or any other condition of the conditions for accepting the temporary problems, then the court to which the problem was brought, if it was made before it by not accepting it, should examine the payment and rule on it not to accept the problem if the seriousness of the payment is determined.

3) It is not permissible to consider the problem due to a previous chapter in it:

If the problem has already been examined by the same facts by a competent authority, and this body has decided on it, then the court to which the problem is referred must not consider it and rule on the inadmissibility of examining the problem for the previous decision.

\section{4- The ruling to leave the litigation in the problem:}

The problem in implementation is like any lawsuit whose motive aims to achieve his personal interest. If the problem is raised and while he is looking as much as the problematic, this problem will not achieve the desired interest for him as if the respondent against him executed the judgment issued in his favor or waived his problem in implementation, then It will not be of any benefit to his insistence on going through his problems.

The ruling to suspend the execution of the judgment in which the question is in question:

The complainant bases his problem in which he requests a stay of execution of the judgment to be executed on several reasons:

1) That the judgment to be executed was issued in violation of the law.

2) That the judgment to be executed is not final.

3) That the judgment in which its implementation was questioned was issued null for violating the law.

4) If the problem is based on serious reasons, which the execution chief, after examining from the appearance of the papers, determines that they are so, then he shall order the suspension of the execution.

The ruling to continue implementing the judgment in which the judgment is in doubt:

The party in whose favor the judgment is issued may raise a problem in the implementation of the positive problems in order to continue the implementation until its end, which is to obtain the right fixed by the executive document, the failure of the executor or the executor against him from the implementation of the executive document is a legal impediment that permits the applicant to complain about it, requesting granting him a temporary protection represented in continuing with Implementation. ${ }^{2}$

The judgment issued in the temporary confusion possesses the authority of the adjudicated order immediately after its issuance so that it is not permissible to raise what is decided in it again, except that it differs from the substantive judgments in its nature because it is an urgent judgment related to certain circumstances that do not tolerate delay or slowdown in litigation procedures. The shortest time for granting effective temporary protection to whoever requests it is either to prevent him from executing in violation of the law or to remove the obstacles that the enforcer or the executor has placed against him or the executor of the obstacles to implementation without legal authority. ${ }^{3}$

The judgment issued in the provisional problem has the authority of the adjudged order, as does the judgment issued in the merits case. The question that arises, how to appeal the temporary problems, I will explain that in the second requirement.

\section{The second requirement:}

\section{Ways to appeal the judgment issued in temporary problems}

The Jordanian legislator stipulated in Article (9) of the Jordanian Execution Law that: "Bonds may not be enforced as long as it is permissible to challenge them unless the expedited execution is stipulated in the law or is governed by it."

The Jordanian Court of Cassation ruled: "The chief executioner is the only competent authority to grievance against the decisions issued in procedural cases, and he has the right to revoke the objected decision and amend it as the case requires, and his decisions in this regard are subject to appeal."4

Article (20) of the Execution Law permits the parties to the execution problems to appeal the decision issued by the head of execution before an appeals court and within seven days following the date of his notification of

\footnotetext{
${ }^{1}$ Al-Husseini, Cases of Execution, pp. 81-82.

${ }^{2}$ Dhahiri, Temporary Implementation Problems Related to the Implementation of Judgments of the State Council Courts, p. 147.

3 Al-Husseini, Cases of Execution, pp. 81-82.

4Jordanian Court of Cassation Decision No. 741/96 of 1997, Jurisprudence, p. 124, referred to in: Al-Aboudi, Explanation of the Provisions of the Execution Law, p. 180.
} 
the ruling mentioned in this article a general ruling that includes every decision issued by the chief of execution. In implementation of this the Jordanian Court of Cassation ruled that: "If The distinguished person submitted to the head of the implementation of the beginning of Amman a request to suspend the execution of the executive case, and the chief executioner issued his decision to reject the request, and he appealed this decision to the Amman Court of Appeal, where it issued its decision to dismiss the appeal, because the decision issued by the Amman Court of Appeal subject to this appeal is considered a final decision pursuant to the provisions of Article 20 / B) From the Temporary Execution Law No. 36 of 2002, and therefore the appeal is not accepted before the Court of Cassation, neither with permission nor without permission, which must be rejected in form. ${ }^{1}$

\section{Conclusion}

The implementation problems are a means that the law gives to the parties to the implementation and to others in order to enable them to present their claims before the execution judiciary if the elements of the execution, its introductions, or its procedures have flaws affecting its safety, with the intention of preventing, stopping or nullifying the implementation that is not in accordance with the law and the most important results that we have reached in this The humble research are:

- The Jordanian legislator has regulated temporary implementation problems and subjected the rest of the disputes to the general rules, and this is clear in the text of Article 19 of the Jordanian Execution Law No. 25 of 2007.

- The Jordanian legislator assigns the authority to adjudicate implementation problems according to the type of problem, as we find jurisdiction in looking at it dispersed between the judicial authorities, according to whether the executive problem is objective or temporary and according to whether it is related to implementation procedures or not related to implementation procedures. The general rule in Jordanian law is in In this regard, the chief executioner is the only one competent to settle the problems encountered in implementation. And according to the Jordanian Implementation Law No. (36) for the year 2002, which defined the terms of reference of the implementation chief.

- The head of execution shall be decided on temporary implementation problems according to the text of Article (18) of the Jordanian Execution Law in his capacity as a judge for urgent matters. Therefore, his jurisdiction over these disputes is limited to the temporary procedures that he fears from the lapse of time in order to ward off an imminent danger or to maintain a legitimate actual situation or maintain a center Existing legal, without prejudice to the origin of the right

\section{Recommendations:}

- The position of the Jordanian legislator to keep the original in the procedures for raising temporary implementation problems, so that they are brought before the head of execution with the usual procedures for filing urgent lawsuits and the position of the comparative legislation, including the Egyptian legislator who, in addition to the normal way, authorized the possibility of presenting the temporary problem in front of the record during the implementation process in order to achieve many purposes, the most important of which is facilitation The litigants must reconcile between the interest of the requester of execution and the interest of the objector against him, by assisting the opponent who was unable to raise the problem before starting the execution by remedying his matter and providing him with the hand of assistance by authorizing the removal of the problem in the immediate manner before the report during his initiation of execution.

- It is imperative to amend the Jordanian implementation law and include legislative texts that deal with implementation problems and define jurisdiction because the temporary execution disputes are related to implementation procedures and are based on subsequent facts on the establishment of the bond according to which the implementation will take place.

- It is necessary to take into account all the obstacles and problems that may hinder the implementation process. Special provisions must be put in place to facilitate the settlement of these problems as soon as possible until the separation and to remedy the delay in the implementation process.

\section{References}

- Dr. Fathi Wali for Compulsory Execution in Civil and Commercial Articles, Dar Al-Nahda Al-Arabiya for Publishing and Distribution, 1995.

- Dr. Ahmed Abu Al-Wafa (1987), Procedures for Execution in Civil and Commercial Articles, Al Maarif Foundation for Printing and Publishing.

- Dr. Mahmoud Mohamed Dhahry, Temporary Implementation Problems Related to the Implementation of

1 Article (20) of the Jordanian Implementation Law stipulates that: "A. The decision issued by the President is subject to appeal before the Court of Appeal within seven days following the date of its understanding or notification." 
Judgments of the State Council Courts, A Judicial Comparative Analysis Study, 2002, Egypt, State Council.

- Dr. Yunus Thabet, Problems of Execution in Verdicts and Documented Editions, 1972 Edition.

- Dr. Al-Nimr Secretary, Provisions of Forced Execution and its Methods, Alexandria, Knowledge Foundation 1971.

- Dr. Omar Nabil Ismail (Reason for the judicial request before the Court of Appeal, Arabic translation of a PhD thesis, 1987 Edition)

- Dr. Ben Malha Al-Ghouthi (Urgent Judiciary and its Applications in the Algerian Judicial System, National Bureau for Educational Works, 2000.

- Dr. Abu Al-Wafa, The Theory of Defenses, University Press, 2012

- Al-Minshawi, Abdel-Hamid, Execution Problems in Civil and Commercial Matters, The Legal System for Executing Arbitrators' Internal Judgments, Fouad Ali Al-Qahali, Law and Economics Library, Riyadh, 1st Edition.

- Dr. Anbar, Muhammad, (1988), Al-Wajeez fi Ahkam Al-Muhtari Optional Implementation, 1988 Zahran Press, Cairo.

- Dr. Salhadar, Salah al-Din, (1967), The Principles of Civil Execution.

- Dr. Belghith, Amara, (2004), Forced Execution and Its Problems

- Dr. Abdel Khaleq, (1978), General Principles of Implementation, University Press, Cairo.

- Dr. Ahmed Abu Al-Wafa (1980), Procedures for Enforcement in Civil and Commercial Matters under the Lebanese Code of Procedure.

- Dr. Anwar Tolba, (1996) Forced Execution and Its Substantive and Temporary Disputes, Alexandria, University Office

- Laws Jordanian Implementation Law No. 25 of 2010 and its amendments 2017-2018-2019

- Jordanian Code of Procedure No. 16 of 2006 and its amendments.

- University thesis, Problems of Objective and Temporary Implementation in the Algerian and Jordanian Laws (A Comparative Study), Ibn Amer Bahous Abu Bakr Bouab 2006. 